\title{
Polymethylene-b-poly(acrylic acid) diblock copolymers: morphology and crystallization evolution influenced by polyethyene polyamine with dual confinement effects
}

\author{
Qian He, ${ }^{a}$ Yali Yuan, ${ }^{\mathrm{a}}$ Fengxia Chen, ${ }^{\mathrm{a}}$ Zhi Ma, ${ }^{\mathrm{b}}$ Xingqi Zhu, ${ }^{\mathrm{c}}$ Rui Song ${ }^{\mathrm{a}}$ \\ a College of Chemistry and Chemical Engineering, University of Chinese Academy of Sciences (CAS), Beijing 100049, China \\ b Shanghai Institute of Organic Chemistry, Chinese Academy of Sciences (CAS), Shanghai 200032, China \\ Beijing Application Lab, Bruker China, Beijing 100081
}

\section{A R T I C L E I N F O}

Article history:

Received X 2016

Received in revised form $\mathrm{X}$

2016

Accepted X 2016

Available online X 2016

\begin{abstract}
A B S T R A C T
In this work, we systematically investigated the aggregation and confined crystallization behavior of polymethylene-b-poly acrylic acid diblock copolymers (PM-b-PAA, $\mathrm{M}_{93} \mathrm{~A}_{94}$ ) under the influence of polyethyene polyamine (PPA). With the increasing molar ratio of PPA, the morphologies of PM-b-PAA micelles experienced sphere-to-band-to-sheet transformations with regular changes of sizes on cooling from $80{ }^{\circ} \mathrm{C}$ mixed solution. Further investigation of the crystalline feature of PM-bPAA indicated that the crystallization of PM block was profoundly restrained by PPA with the dual confinements, i.e., chemical and physical confinement which exerted through the hierarchical hydrogen bonding and 3D hydrogel network, respectively, in the mixed system. In particular, when the PPA and PM-b-PAA aqueous solution were mixed with equivalent volume, hydrogels was accessible. And rheology property indicated that the BCP/PPA- 0.5 hydrogels hold the maximal storage modulus $\mathrm{G}^{\prime}$, and meanwhile the minimum loss tangent, $\tan \delta$.
\end{abstract}

\section{Introduction}

In recent years, block copolymers (BCPs) have attracted abiding interest, owing to their various morphologies in bulk or solution, [1-4] which is caused by the thermodynamic incompatibility of the different polymer segments. [5-7] The morphologies are mainly including spheres, cylinders, lamellae and vesicles.[8-10] The ordered nano-structures are widely used in catalysts and drugs delivery as nano-reactors.[8,11,12] Furthermore, microphase separation of block copolymers can form ordered microdomains with dimensions of a few nanometers to hundreds of nanometers, and lamellar or columnar periodically ordered-membrane can be made.[12-14] In all, block copolymers can be spontaneously constructed well-ordered periodic structures and have wide applications in the fields of lithography, industrial catalysis, biomedical, and optoelectronics technology. $[5,8,15,16]$

As one unique species, semi-crystalline BCPs, which contain at least one crystallizable chain segment, have aroused wide concern in the last decade.[17-19] Frequently used crystalline block components are polyethylene (PE),[1,20-22] polyethylene oxide (PEO)[20-24] and polycaprolactone (PCL).[20,23,25] Except for microphase separation and solvophilic/solvophobic driving forces, crystallization can be viewed as another driving force for the self-assembly. Therefore, immense morphological differences between the crystalline BCPs and amorphous BCPs could be observed experimentally. Previous works have found that crystalline BCPs prefer to form structures with low interfacial curvature such as cylinders, worm-like, platelets and other complex nanostructures.[26-28] However, it is relatively difficult to form these uniform and asymmetric micellar structures in amorphous BCPs.[19] And these asymmetric structures have a wide range of applications. For example, the optical band gap of lamellar photonic crystals can be significantly shifted by swelling/shrinking one layer,[29] and the adaptive domain spacing has proven advantageous to transfer printing techniques for micro/nano-device fabrication.[30] In consideration that the crystallization is kinetics control process, required structures can be obtained by designing the molecular structure and regulating the external assembly conditions.[31]

However, compared with amorphous BCPs, the research of crystalline BCPs is still not deep and systematical enough. Currently, researches on the semi-crystalline BCPs are mainly concentrated in the following respects: 1), to regulate the self-assembly morphologies of crystalline BCPs by chain structures and various external parameters, which change the relative strength of crystallization and other driving forces in the bulk, in thin film and in solution.[5,8] For example, He et al investigated the effect of inorganic salt on the micellar morphology of semicrystalline PCL-b-PEO in aqueous solution, and the results indicated that the inorganic salt can induce sphere-to-rod or sphere-to-lamella transformations of the PCL-b-PEO micelles in aqueous solution, which can be explained with the reduced tethering density $(\tilde{\sigma}) .[32]$ 2 ), some studies on highly asymmetric lamellar structures,[33] single crystals,[5,8] co-micelles[26,34] or controlled growth of semi-crystalline micelles [5,26] in which aggregation, crystallization are 'free' in the absence of other chemicals. 3), multicompartment and multigeometry nanoparticle assemblies are also reported by Chen and coworkers, they constructed complex nanostructures by simply blending PAA-b-PI and PAA-b-PS.[35]

Our recent investigation on the polymethylene-b-poly (acrylic acid), PMb-PAA, found that it could form disk-like micelles in DMF solution, in which crystalline polymethylene folded as a core. And the confined crystallization of 
polymethylene was influenced distinctly by the noncrystallizable PAA block. Contrastively, well-defined lozenge-shaped single crystals could be prepared via the self-seeding process in dilute DMF solution at $50{ }^{\circ} \mathrm{C}$.[5] It should be noted that this investigation was conducted under the state that BCPs chains were relatively undisturbed, i.e., the crystallization of PM block was developed under appropriate conditions, including proper crystallization temperature, good solvent and no external force. And the flexible and regular structure thus confer the PM block with strong crystallizing liability. So what will happen if some external disturbance, like polar amine organics, is introduced to the undisturbed state mentioned above? From this context, we try to investigate the aggregation and crystallization behavior of $\mathrm{BCP}$ with the impact of amine organic

As well known, many interference factors such as temperature, organic solvent, inorganic salt, et al, would affect BCPs functions and properties in practical applications.[5,32] Here, we just simulated a complicated environment, aiming to figure out the crystallization and aggregation behavior of BCP. Hence, we explore the crystallization and aggregation behavior of the novel semi-crystalline $\mathrm{BCP}\left(\mathrm{PM}_{93}-\mathrm{b}-\mathrm{PAA}_{94}, \mathrm{M}_{93} \mathrm{~A}_{94}\right)$ in the presence of organic amine compound, polyethyene polyamine (PPA). On one hand, the chain-folding of PM block was restricted by the chemically tethered amorphous PAA block, and the amino of PPA interacted with the carboxyl of PAA, forming hydrogen bond $\left(\mathrm{COOH}^{\cdots} \mathrm{N} / \mathrm{COO}^{-\cdots} \mathrm{H}\right)$ or ionic bond $\left(\mathrm{COO}^{-}\right.$ $\cdot \mathrm{NH}_{\mathrm{n}}{ }^{+}, \mathrm{n}=1,2,3$ corresponding to the protonation of $\mathrm{N}, \mathrm{NH}, \mathrm{NH}_{2}$, respectively), which could play a 'chemical confinement' on the movement of PM moiety. On the other hand, PPA, PM-b-PAA and $\mathrm{H}_{2} \mathrm{O}$ interact with each other via hydrogen bonds, and these 'hierarchical hydrogen bonds' will generate a combined gel-like network structure which imposes a 'physical confinement' on the movement of PM blocks. In this case the word 'hierarchical hydrogen bonds' means the coexistence of hydrogen bonds with different bonding strength, like $\mathrm{N}-\mathrm{H}^{\cdots} \mathrm{N}, \mathrm{COO}^{\cdots \cdots} \mathrm{H}, \mathrm{H} \cdots \mathrm{N}-\mathrm{H} .[36]$ These dual confinements would collectively affect the self-assembly and crystallization behavior of crystalline micelles. In this case, the overall crosslinking force provided by these hierarchical interactions could be tuned by tailoring the ratios of BCP to PPA components. In addition, with the increase of PPA molar ratio, the morphology of PM-b-PAA changed regularly, and the crystallization of BCP became less liable. Meanwhile, as the rheological measurement suggested the PPA hydrogels became more stable with the addition of moderate $\mathrm{BCP}$, in which PM blocks could fold to form crosslinking points.

\section{Experimental}

\subsection{Materials and chemicals}

Block copolymers (BCP), polymethylene-b-poly(acrylic acid) ( $\mathrm{PM}_{93}-\mathrm{b}-$ $\mathrm{PAA}_{94}$ ) was prepared by living polymerization of ylides and atom transfer radical polymerization (ATRP). Details about synthesis and structure characterization can be found elsewhere.[37] Number-average molecular weight $\left(\mathrm{M}_{\mathrm{n}}\right)$ is 8800 , polydispersity index (PDI, $\left.\mathrm{M}_{\mathrm{w}} / \mathrm{M}_{\mathrm{n}}\right)$ is ca. 1.10 . Deionized water $(18.2 \mathrm{M} \Omega \mathrm{cm})$ was produced by ultrapure water systems (Ulupure Co. Ltd., Shanghai, China). Polyethyene polyamine (PPA, $\mathrm{C}_{2 \mathrm{n}} \mathrm{H}_{5 \mathrm{n}} \mathrm{N}_{\mathrm{n}}$ ), Aladdin, China

\subsection{Sample preparations}

In the colloid system, generally, PM-b-PAA $(7.5 \mathrm{mg})$ was heated and stirred in ultrapure water $(15 \mathrm{ml})$ for $2 \mathrm{~h}$ at $80{ }^{\circ} \mathrm{C}$, which was close to the melting temperature $\left(\mathrm{T}_{\mathrm{m}}\right)$ of PM. Then, different amounts of PPA were added dropwise to the as-prepared $\mathrm{BCP}$ solution, in a molar ratio $\left(\mathrm{n}_{\mathrm{PPA}} / \mathrm{n}_{\mathrm{BCP}}\right)$ of 0 , 1:5, 1:1. 320:1, 1280:1, 1920:1, e.g., $\mathrm{n}_{\mathrm{PPA}} / \mathrm{n}_{\mathrm{BCP}}=1: 5$, was denoted as $\mathrm{B}_{5} \mathrm{P}_{1}$. Particularly, BCP was denote as B and PPA was denoted as P. And the mixed solutions were stirred thoroughly for $30 \mathrm{~min}$, following by being cooled down to room temperature at a rate of $\sim 0.5^{\circ} \mathrm{C} \mathrm{min}^{-1}$ and stirred for another $24 \mathrm{~h}$ at the ambient condition. Finally, the mixed solutions with different $n_{P P A} / n_{B C P}$ values were obtained for further analysis (Fig. S1).

In the gel system, a range of different amounts of BCP $(0 \mathrm{mg}, 5 \mathrm{mg}, 10$ $\mathrm{mg}, 25 \mathrm{mg}, 50 \mathrm{mg}$ ) were separately heated and stirred in ultrapure water $\left(80{ }^{\circ} \mathrm{C}, 5 \mathrm{ml}\right.$ ) for $2 \mathrm{~h}$, and then $5 \mathrm{ml}$ PPA was added to each of the as-prepared BCP solutions, and the mixed were stirred well for $30 \mathrm{~min}$. Next, cooled down to room temperature at a rate of $\sim 0.5{ }^{\circ} \mathrm{C} \mathrm{min}{ }^{-1}$ and the gelatin time was recorded (Table S1). In the subsequent tests, the prepared samples were denoted as BCP/PPA-x, where $\mathrm{x}$ is the concentration of $\mathrm{BCP}$, and the volume ratio $(\mathrm{V} / \mathrm{V})$ of $\mathrm{BCP}$ relative to PPA was constant 1:1 for all samples.

\section{Results and discussion}

\subsection{Colloid system}

Herein, we choose water as solvent for the preparation of PM-b-PAA aggregates, with crystalline PM as the core and solvated PAA as the corona on cooling the homogeneous solution from $80{ }^{\circ} \mathrm{C}$. While, the BCP/PPA solutions were prepared from the $\mathrm{M}_{93} \mathrm{~A}_{94} /$ water solution with different molar ratios of PPA being added before cooling step. The detailed aggregation, crystallization behavior and the mechanisms are discussed as follows:

Aggregation and crystallization of PM-b-PAA depending on PPA. In order to investigate the effect of PPA on the morphology and crystallization evolution of semi-crystalline PM-b-PAA diblock copolymers in solution, a series of BCP/PPA mixed solutions with different molar ratios were prepared, i.e., $\left(\mathrm{n}_{\mathrm{PPA}} / \mathrm{n}_{\mathrm{BCP}}\right)$ of $0,1: 5,1: 1.320: 1,1280: 1,1920: 1$. SEM and polarized optical microscopy (POM) were performed to explore the morphology and crystallization behavior of samples.

We can clearly see the regular change of the morphologies despite the blurred electron microscopy images owing to the intractable viscous organic amine PPA. As seen in Fig. $1 \mathrm{~A}_{1}-\mathrm{F}_{1}$, the spin-coated $\mathrm{M}_{93} \mathrm{~A}_{94}$ samples tended to form spherical shape aggregates, which were also detected in AFM observations (Fig. S2). When a small amount of PPA (i.e., the molar ratio of amino and carboxyl is less than 1) was added into the as-prepared BCP solution, $\mathrm{M}_{93} \mathrm{~A}_{94}$ aggregated into micelles mainly with an oval morphology (Fig. $1 B_{1}$ ). With increasing molar ratios of PPA, from 320:1 to 1920:1, the morphology of $\mathrm{M}_{93} \mathrm{~A}_{94}$ evolved from sphere, band to sheet. Moreover, POM was utilized to characterize the crystalline morphology of different BCP/PPA films (Fig. 1 $\mathrm{A}_{2}-\mathrm{F}_{2}$ ). As indicated, all the samples presented specific crystal polarizing phenomenon, and the crystal became small after adding PPA Meanwhile, the band and sheet-like morphologies were depicted by the black circles in Fig. $1 \mathrm{E}_{2}-\mathrm{F}_{2}$, which were highly consistent with the SEM results. Moreover, the change of morphology was also confirmed by AFM image in Fig. S2.
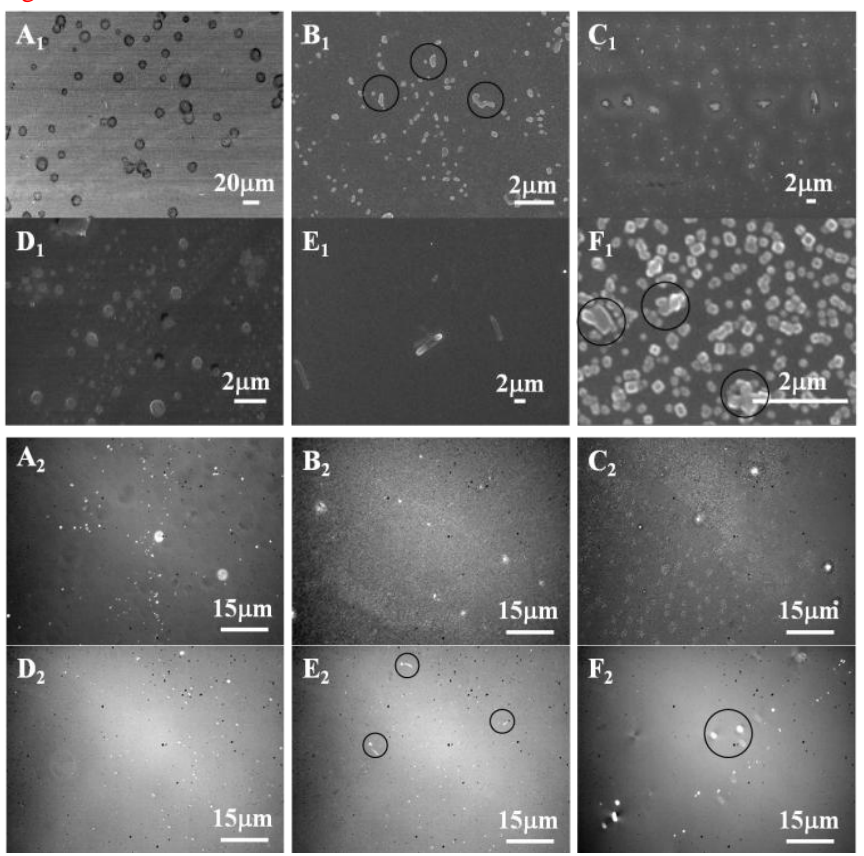

Fig. 1 SEM $\left(A_{1}-F_{1}\right)$, POM $\left(A_{2}-F_{2}\right)$ images of PPA/M $M_{93} A_{94}$ samples prepared with different PPA molar ratios, A-F represent the samples with $\mathrm{n}_{\mathrm{PPA}} / \mathrm{n}_{\mathrm{BCP}}$ values of $0,1: 5,1: 1.320: 1,1280: 1$, 1920:1, respectively. $\mathrm{c}(\mathrm{BCP})=0.5 \mathrm{mg} \mathrm{ml}^{-1}$ 
Furthermore, in order to clear the relationship between the aggregation behavior of PM-b-PAA and the mount of PPA, the change of hydrodynamic diameters $\left(D_{h}\right)$ and zeta potentials $(\zeta)$ in the BCP/PPA aqueous solution were investigated by dynamic laser scattering (DLS) test (Fig S3). The $\mathrm{D}_{\mathrm{h}}$ values experienced a significant decrease from $\sim 213.5 \mathrm{~nm}$ to $\sim 148.3 \mathrm{~nm}$ with increasing $\mathrm{n}_{\mathrm{PPA}} / \mathrm{n}_{\mathrm{BCP}}$ from 0 to $1280: 1$; while, an obvious increase in $\zeta$ data was noticed from $-8.54 \mathrm{mV}$ to $-29.1 \mathrm{mV}$ (Table 1), suggesting the system tended to be more stable. This observation could be attributed to the more effective negative charge repulsion from $\mathrm{COO}^{-}$after adding PPA and the interaction between PPA and $\mathrm{COO}^{-}$, which collectively made the system more stable. As schematically given in Fig. 2, the PAA chain was initially collapsed and PPA could only interacted with carboxylic groups protruded on the surface of BCP micelles with dominate ionic bonds. Meanwhile, the PPA would further promote the ionization of PAA, leading to a downtrend in $\mathrm{pH}$ values (Table 1). With further increasing of PPA molar ratio, carboxyl groups were deprotonated, PAA was gradually extended, PPA and PAA block could thus interact well with dominate hydrogen bonding, giving a uptrend in $\mathrm{pH}$ value (Table 1). Simultaneously, PAA block was not fully extended and would take the optimal conformation owing to the interaction between $\mathrm{COO}^{-}$ and PPA. The PAA blocks, therefore, became intertwined with PPA molecules. Meanwhile, the interaction between $\mathrm{PPA}$ and $\mathrm{COO}^{-}$would restrict the crystallization of PM block, which will be verified in more detail below. As a consequence, the $D_{h}$ values gradually decreased as $n_{P P A} / n_{B C P}$ increased from 0 to 1280:1. When $\mathrm{n}_{\mathrm{PPA}} / \mathrm{n}_{\mathrm{BCP}}=1920: 1$, the multi-hydrogen bonds made the aggregate inflated with the hydrate particle size slightly increasing.

Table 1 Hydrodynamic diameters $\left(\mathrm{D}_{\mathrm{h}}\right)$, zeta potentials $(\zeta)$ and $\mathrm{pH}$ values of $0.5 \mathrm{mg} \mathrm{mL}{ }^{-1} \mathrm{M}_{93} \mathrm{~A}_{94}$ aqueous solution with $\mathrm{n}_{\mathrm{PPA}} / \mathrm{n}_{\mathrm{BCP}}$ values of $0,1: 5,1: 1.320: 1,1280: 1,1920: 1$, respectively

\begin{tabular}{ccccc}
\hline Sample code & $\mathrm{n}_{\mathrm{PPA}} / \mathrm{n}_{\mathrm{BCP}}$ & $\mathrm{D}_{\mathrm{h}}(\mathrm{nm})$ & $\zeta(\mathrm{mV})$ & $\mathrm{pH}$ \\
\hline $\mathrm{B}$ & 0 & 213.5 & -8.54 & 4.68 \\
$\mathrm{~B}_{5} \mathrm{P}_{1}$ & $1: 5$ & 174.0 & -16.2 & 3.78 \\
$\mathrm{~B}_{1} \mathrm{P}_{1}$ & $1: 1$ & 160.5 & -19.2 & 3.67 \\
$\mathrm{~B}_{1} \mathrm{P}_{320}$ & $320: 1$ & 157.9 & -27.4 & 10.28 \\
$\mathrm{~B}_{1} \mathrm{P}_{1280}$ & $1280: 1$ & 148.3 & -29.1 & 10.20 \\
$\mathrm{~B}_{1} \mathrm{P}_{1920}$ & $1920: 1$ & 160.5 & -25.7 & 10.56 \\
\hline
\end{tabular}

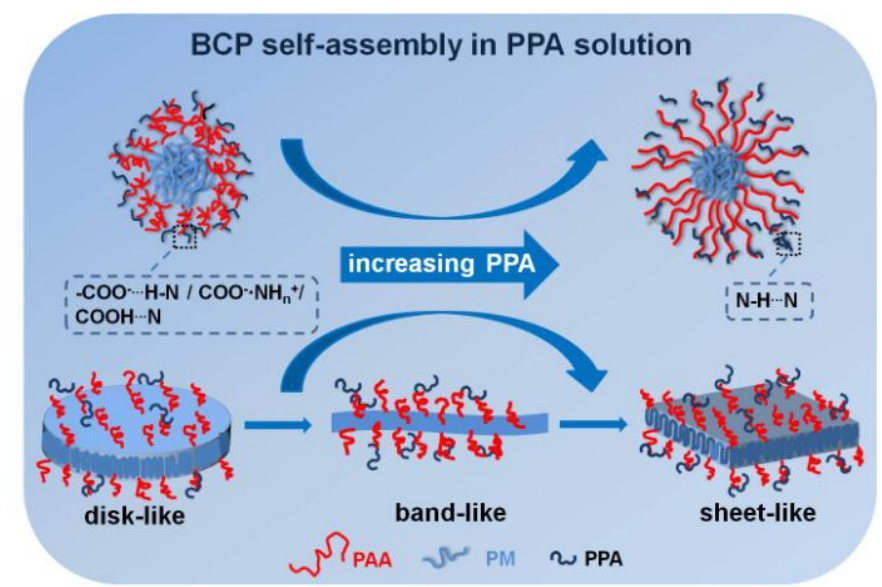

Fig. 2 Schematic representation of the aggregation and crystallization behavior of $\mathrm{M}_{93} \mathrm{~A}_{94}$ under the influence of PPA.

Sphere-to-band-to-sheet transformations in morphology of PM-b-PAA with different contents of PPA could also be schematically depicted in Fig 2. In the mixed system, there are mainly two type interactions, i.e., relatively strong ionic bonds of $-\mathrm{COO}^{-\cdots} \mathrm{NH}_{\mathrm{n}}{ }^{+}$- between anionic carboxylic groups of BCP and cationic amino groups of PPA molecules, and relatively weak hydrogen bonds among PPA molecules, PPA with $\mathrm{H}_{2} \mathrm{O}$ and BCP with PPA.
The aggregation behavior as a function of the molar ratios of PPA could be explained with the reduced tethering density $\tilde{\sigma},[5,32]$ which is defined by $\sigma \pi \mathrm{R}_{\mathrm{g}}{ }^{2}$ (where $\sigma$ is the tethered chain density and is equal to the reciprocal of the covered area of soluble chains, $R_{g}$ is the radius of gyration of a free soluble block). At a larger $\bar{\sigma}$, spherical micelles tended to be formed, but lamellar micelles were formed at a smaller $\sigma .[32]$ When PPA was absent from the solution, the $\tilde{\sigma}$ was larger, and the amorphous PAA chains would collapse and cover around the folding surface of PM block. Therefore, the PM chains folded uniformly and spherical micelles were formed. In contrast, when PPA was added, repulsion between $\mathrm{COO}^{-}$would cause a decreasing $\sigma$, and the entangled state of PAA and PPA would bring about a small increase of $\mathrm{R}_{\mathrm{g}}$ of

PAA chains. Considering these two aspects, the $\tilde{\sigma}$ finally became smaller after addition of PPA. And the morphologies, as shown in Fig. $1 A_{1}-F_{1}$, with low interfacial curvature (such as bands and sheets) which favorable in such a situation were formed.[5] It should be noted that the ellipsoidal structure $\left(\mathrm{n}_{\mathrm{PPA}} / \mathrm{n}_{\mathrm{BCP}}=1: 5\right)$ can be viewed as the intermediate morphology between spheres and bands.
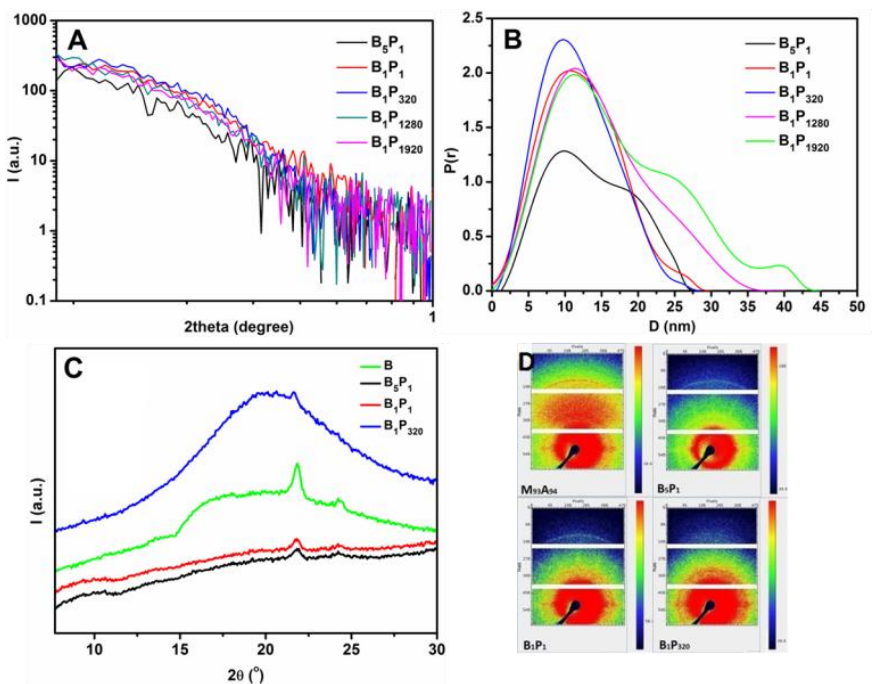

Fig. 3 SAXS (A) and pair distance distribution function (PDDF) profiles (B); WAXS curves (C) of $\mathrm{M}_{93} \mathrm{~A}_{94}$ and BCP/PP A mixed samples and 2D (two-dimensional) WAXS patterns (D). c(BCP) $=0.5 \mathrm{mg} \mathrm{ml}^{-1}$.

X-ray technique, including SAXS and WAXS, could supply more direct and statistic information concerning the aggregation and crystallization. Small-angle X-ray scattering (SAXS) experiments, which reflects the information about the large-scale order structure and density fluctuations, were carried out to determine the aggregate structure of BCP in the mixed solution. Firstly, the SAXS curves showed the scattering capacity of each sample was highly similar (Fig. 3A). To further evaluate the polymer shape and dimensions, the pair distance distribution functions (PDDF) which represent the values of distances within the particle for homogenous particles and the difference electron density at the volume element should be considered for inhomogeneous particles [37,39], were calculated through the inverse Fourier transformation of SAXS curve by which the micelle sizes could be derived (Fig. 3B). It was evident that micelle size experienced an increase from $\sim 26 \mathrm{~nm}$ to $\sim 38 \mathrm{~nm}$ with $\mathrm{n}_{\mathrm{PPA}} / \mathrm{n}_{\mathrm{BCP}}$ increasing from 1:5 to 1280:1. Moreover, the radius of gyration $\mathrm{R}_{\mathrm{g}}$ were obtained by calculating the PDDF curves using the software of DIFFRAC.SAXS. With increasing of PPA molar ratio, the values of $\mathrm{R}_{\mathrm{g}}$ were $10.4 \mathrm{~nm}, 9.49 \mathrm{~nm}, 9.01 \mathrm{~nm}, 11.6 \mathrm{~nm}, 13.6 \mathrm{~nm}$, respectively. When PPA was absent from the solution, most of carboxylic acid groups existed in uncharged - $\mathrm{COOH}$ form, and the PAA chains would accordingly tethered on the surface of the PM crystals, thus the mass center of $\mathrm{BCP}$ was close to every chain unit which resulted in a smaller $\mathrm{R}_{\mathrm{g}}$. In the presence of PPA, however, the PAA chains swelled and fully extended, and 
the mass center of BCP was far from every chain unit which resulted into a larger $\mathbf{R}_{\mathrm{g}}$.

It is noteworthy that a notable difference exist between the SEM/POM and DLS/SAXS results. For the morphological observation, either SEM or POM, dry sample films prone to aggregate and even grew further; while in the DLS/SAXS test the particles are in liquid state. More specifically, DLS obtains the hydrodynamic diameters and SAXS is focus on electronic density difference. In this case, the electron density is much more close for corona PAA and PPA, but more different for PM and PAA. So, it is very probably reflect the PM size which is smaller than hydration size measured by DLS.

The shape of the particles could be differentiated by close checking the PDDF curve characteristics (Fig. 3B). With the increasing of PPA molar ratio, the tails of PDDF curves began to appear, indicating the structure of the particles turned from sphere to nanoparticles which had a bigger length to diameter ratio, like columnar, band-like particles and so on. Specifically, the data for $\mathrm{B}_{1} \mathrm{P}_{1280}$ present an overshoot and a nearly linear tail in the PDDF, implied that the BCP were bands.[39] Meanwhile, the PDDF curves had two peaks for $\mathrm{B}_{5} \mathrm{P}_{1}$ and $\mathrm{B}_{1} \mathrm{P}_{1920}$, indicating that the particles accumulated together in Fig. $1 \mathrm{~B}_{1}$ and $\mathrm{F}_{1}$ (shown with the black circles). And for $\mathrm{B}_{1} \mathrm{P}_{320}$, the PDDF curve had a symmetrical inverse bell structure, illustrating spherical particles were obtained.[40,41] These results concerning the shape of BCP, therefore, were consistent with the above mentioned SEM images. In addition, the area under the PDDF curve increased gradually with the increasing of PPA molar ratio, suggesting that the scattering capacity of the nanoparticles was also increased.

WAXS measurement were performed to get information about the crystallization structure of PM block. The diffraction peaks located at about $21.8^{\circ}$ and $23.8^{\circ}$ were due to crystallization of the PM block which had the identical crystallization structures of bulk polyethylene (Fig. 3C).[5] Despite the similar diffraction peak positions, as indicated, the diffraction intensity was dramatically attenuated with the increasing of PPA molar ratio as compared to neat BCP. The arc crystal reflection patterns in the 2D WAXS were gradually weakened (Fig. 3D), which clearly demonstrated that PPA prevented the PM block reorganizing into well-ordered crystalline structure. And this observations are verified with the following DSC results.
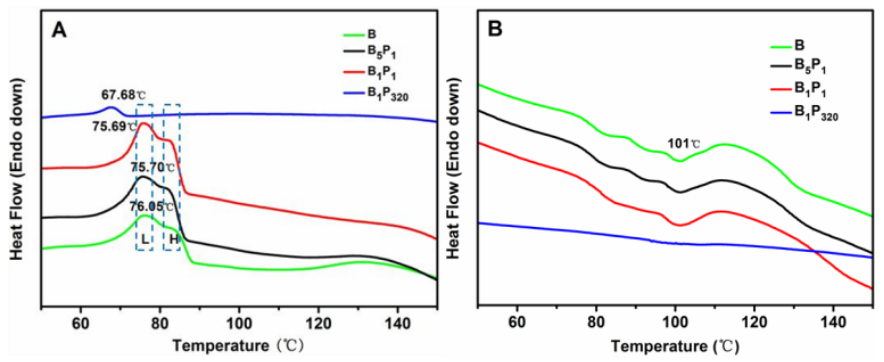

Fig. 4 DSC cooling (A) and re-heating (B) traces of $\mathrm{M}_{93} \mathrm{~A}_{94}$ powder and BCP/PPA freeze-dried micelles with $\mathrm{n}_{\mathrm{PPA}} / \mathrm{n}_{\mathrm{BCP}}$ values of $0,1: 5,1: 1.320: 1$, respectively. The heating rate is $10.0{ }^{\circ} \mathrm{C} / \mathrm{min}$. $\mathrm{c}(\mathrm{BCP})=0.5 \mathrm{mg} \mathrm{ml}^{-1}$.

To further probe the crystalline behavior of PM-b-PAA under the influence of PPA, four different samples were calorimetrically characterized via DSC measurements (Fig. 4). As indicated, the BCP bulk and BCP/PPA samples except for $\mathrm{B}_{1} \mathrm{P}_{320}$ showed obvious melting and crystallization peaks, which could be conclusively assigned to the crystallizable PM block. In addition, with the increasing of $n_{\mathrm{PPA}} / \mathrm{n}_{\mathrm{BCP}}$ value from 0 to 320 , the crystallization temperature $\left(\mathrm{T}_{\mathrm{c}}\right.$ ) decreased from $\sim 76.1^{\circ} \mathrm{C}$ to $\sim 67.7^{\circ} \mathrm{C}$ (Fig. $4 \mathrm{~A}$ ). This observation can be ascribed to the chain-folding confinement of the crystallizable PM block by the chemically tethered amorphous PAA block, which interacted with PPA via hydrogen bonds and/or ionic bonds. Thus, PPA indirectly prevented the PM block reorganizing into well-ordered crystalline structure during the cooling process, which was in accordance with the above WAXS result (Fig. 3C). Furthermore, the movement of PM blocks was also affected by the confinement of the incomplete network structure formed with the multiple interactions in the system.
Notably, with $\mathrm{n}_{\mathrm{PPA}} / \mathrm{n}_{\mathrm{BCP}}$ value from 0 to $1: 1$, the double peaks appeared in the cooling curve, corresponding to a high-temperature peak $(\mathrm{H})$ and a lowtemperature (L), respectively (Fig. 4A). With the increasing of $n_{\mathrm{PPA}} / \mathrm{n}_{\mathrm{BCP}}$ from 0 to 320 , peak $\mathrm{H}$ was gradually decreasing until merging into unimodal with peak $\mathrm{L}$. This phenomenon could be interpreted that the crystallization of PM block would be severely impeded when excessive PPA was incorporated. And this behavior is evidenced vividly in the case of $\mathrm{B}_{1} \mathrm{P}_{320}$, in which no detectable endothermic peak in Fig. 4B, along with the very weak crystallization peak (ca. $0.62 \mathrm{~J} / \mathrm{g}$ ) as compared with BCP (ca. 12.30 J/g) in Fig. 4A.

The interaction between BCP and PPA. UV-vis absorption spectra and NMR were utilized to identify the interaction between BCP and PPA and gained a better understanding of the mixed system. The UV-vis results of 0.5 $\mathrm{mg} \mathrm{mL}^{-1} \mathrm{M}_{93} \mathrm{~A}_{94}$ aqueous solution with $\mathrm{n}_{\mathrm{PPA}} / \mathrm{n}_{\mathrm{BCP}}$ value of $0,1: 5,1: 1,320: 1$, 1280:1, 1920:1 were shown, respectively (Fig. 5A). The maximum UV absorption wavelengths of the PPA were $\sim 289, \sim 335 \mathrm{~nm}$. When $\mathrm{n}_{\mathrm{PPA}} / \mathrm{n}_{\mathrm{BCP}}=1: 5$ and $1: 1$, the interaction were mainly ionic bonds. Upon increasing to 320 or greater, a strong basic environment formed (Table 1). As a result, most of amino groups existed in $-\mathrm{NH}_{2}$ form and nearly all carboxylic acid groups existed in $-\mathrm{COO}^{-}$form. It should be noted that the interaction between $-\mathrm{COO}^{-}$ and $-\mathrm{NH}_{2}$ were hydrogen bonds with dominate electrostatic components.[35] The interaction between BCP and PPA was strong enough to cause the distinct blue-shift of the absorption band to $\sim 280 \mathrm{~nm}$ in the UV-vis spectrum when $\mathrm{n}_{\mathrm{PPA}} / \mathrm{n}_{\mathrm{BCP}}=1280: 1$ and 1920:1.[41] When $\mathrm{n}_{\mathrm{PPA}} / \mathrm{n}_{\mathrm{BCP}}$ further increasing to 1920, the characteristic absorbance peak was not further shifted, since the interactions between PPA and BCP were saturated.[42]

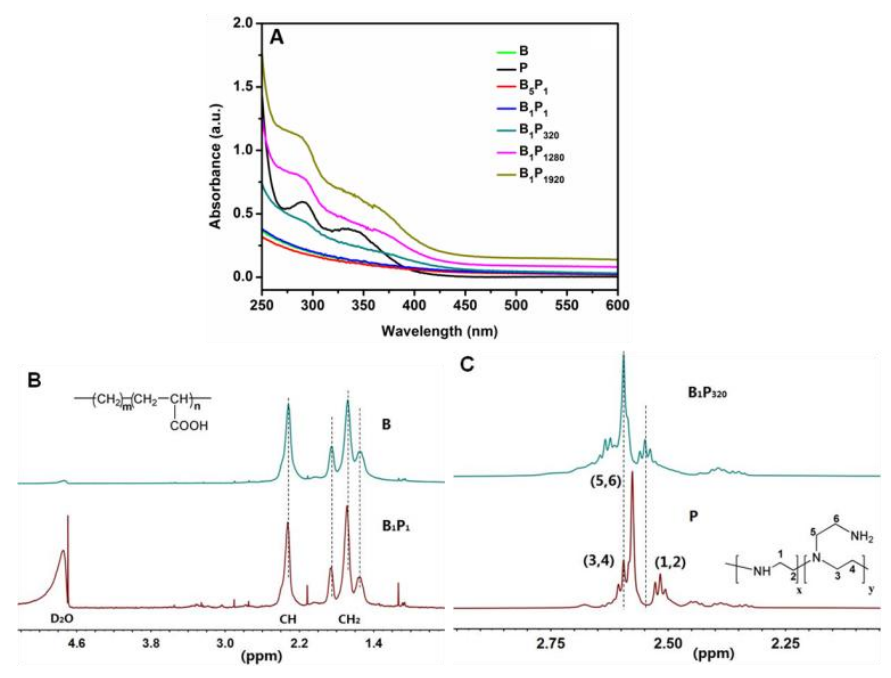

Fig. 5 UV-vis absorption spectra (A) of $0.5 \mathrm{mg} \mathrm{mL}^{-1} \mathrm{M}_{93} \mathrm{~A}_{94}$ aqueous solution with $\mathrm{n}_{\mathrm{PPA}} / \mathrm{n}_{\mathrm{BCP}}$ values of $0,1: 5,1: 1.320: 1,1280: 1,1920: 1$, respectively; ${ }^{1} \mathrm{H}$ NMR spectra $(600 \mathrm{MHz})$ of the samples with $\mathrm{n}_{\mathrm{PPA}} / \mathrm{n}_{\mathrm{BCP}}$ values of $0,1: 1$ (B); 320:1, and neat PPA (C), respectively. $\mathrm{c}(\mathrm{BCP})=0.5$ $\mathrm{mg} \mathrm{ml}^{-1}$.

NMR spectroscopy is also a powerful spectroscopic method that is used to identify structural and functional characteristics of complex molecules in both the solid and liquid states.[43] ${ }^{1} \mathrm{H}$ NMR spectroscopy was utilized to probe the interaction between BCP and PPA. It is a remarkable fact that when the molar ratio of amino and carboxyl is approximately 1 , namely, solution is near the isoelectric point (charge balance), unstable colloidal or precipitation is formed by mixing BCP and PPA. If either chemicals is in excess, a stable colloid phase is obtained.[44, 45] And the samples in this study are all stable colloids with higher molar ratios. Hence, the ${ }^{1} \mathrm{H}$ NMR result was divided into two groups (Fig. 5B, 5C) for comparative purposes. The peaks at ca. 2.32 and $1.54,1.68,1.86 \mathrm{ppm}$ were corresponding to the methyne (-CH-) and methylene (- $\left.\mathrm{CH}_{2}-\right)$ of $\mathrm{BCP}$, respectively (Fig. $\left.5 \mathrm{~B}\right)$. Compared with pure $\mathrm{BCP}$, the signals from $\mathrm{B}_{1} \mathrm{P}_{1}$ slightly moved to high chemical shift (Table S2). A collection of peaks arising from disparate chemical environmental $\mathrm{H}$ of PPA had been marked by the numbers 1-6 in Fig. 5C. Compared with pure PPA, the signals from $\mathrm{B}_{1} \mathrm{P}_{320}$ moved obviously to high chemical shift, which 
attributed to the interactions like hydrogen bonds or ionic bonds between BCP and PPA.[43]

\subsection{Gel system}

With PPA ratio $\left(\mathrm{n}_{\mathrm{PPA}} / \mathrm{n}_{\mathrm{BCP}}\right)$ increasing further, intermolecular weak interactions become cumulated to generate hydrogels. In this study, hydrogels were obtained readily by adding the same volume of BCP aqueous $(0,0.5,1$, $\left.2.5,5 \mathrm{mg} \mathrm{mL}^{-1}\right)$ into the PPA. The synergistic effect of intermolecular weak interactions in the system sufficiently yielded three-dimensional network of the hydrogels, and accordingly, the generated gels will bring non-negligible influence on aggregation and crystallization behavior of BCP.
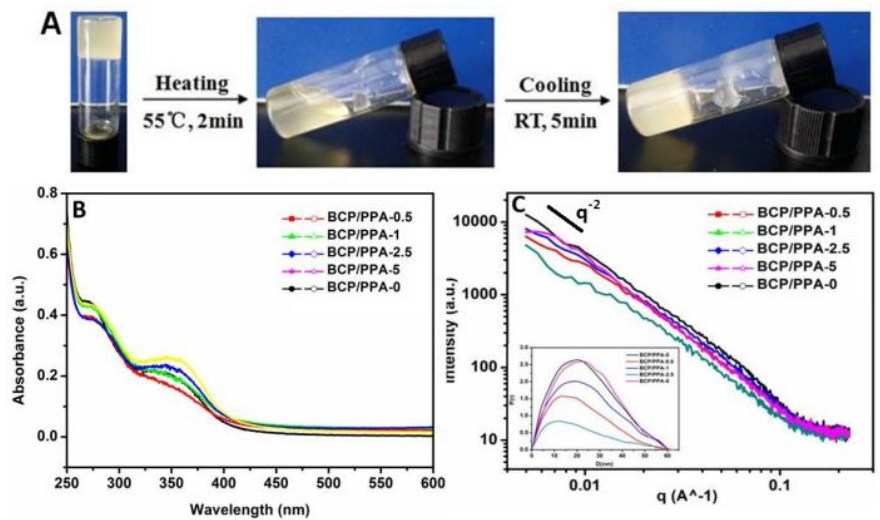

Fig. 6 Digital photographs (A) of temperature induced reversible gel-sol transition of BCP/PPA-0.5 hydrogel. UV-vis absorption spectra (B) of diluted BCP/PPA hydrogels with different concentration of $\mathrm{M}_{93} \mathrm{~A}_{94}$. SAXS curves (inset: PDDF profiles) (C) of BCP/PPA hydrogels with $0,0.5,1,2.5,5 \mathrm{mg} \mathrm{ml}^{-1} \mathrm{BCP} . \mathrm{V}_{\mathrm{PPA}} / \mathrm{V}_{\mathrm{BCP}}=1: 1$

Since a large crosslinking force is provided with hydrogen bonds which are very susceptible to temperature, the obtained hydrogels could undergo the gel-sol transition when heated above a critical temperature (Fig. 6A). The resulting sol reverted back to a gel-like state in minutes after incubation at ambient temperature, and the transition process could be repeated many times. Moreover, the gelatin time of different gels, with the increasing contents of BCP, was gradually shorten (Table S1), qualitatively demonstrated that BCP played a promoted role for the gel's formation.

The existence of interactions in the BCP/PPA hydrogels was evidenced by UV-vis measurement. As shown, the PPA presented a UV-vis peak located at ca. $270 \mathrm{~nm}$, which stemmed from the $n-\sigma^{*}$ transition (Fig. 6B). With more $\mathrm{BCP}$, this absorbance peak red shifted to $\sim 272 \mathrm{~nm}, \sim 273 \mathrm{~nm}, \sim 274 \mathrm{~nm}, \sim 276$ nm respectively (Table 2 ), implying the interactions between BCP and PPA.[41] Additionally, an obvious shoulder peak at $~ 344 \mathrm{~nm}$ appeared which indicated the formation of BCP/PPA aggregates or particles caused the light scattering, or Mie effect.[42]

One interesting thing is the maximum UV absorption wavelengths of the PPA were different in the colloid and gel system, and this observation could be tentatively ascribed to the variation in the preparation process, i.e., the former colloid system was prepared by diluting PPA with water directly; while the latter gel system was firstly prepared to form PPA hydrogel, then diluted with water, in which there may existed network structure constructed by PPA and water. The latter, therefore, needed more energy to stimulate the $n-\sigma^{*}$ transition. Hence, the maximum UV absorption wavelengths of the PPA were blue shift in the gel system $(\sim 270 \mathrm{~nm})$ compared with that of the colloid system ( 289 $\mathrm{nm}, \sim 335 \mathrm{~nm})$.

The conclusion from UV-vis was complemented with the FTIR measurements (Fig. S4). The absorption peaks attributed to hydroxyl ( 3439 $\left.\mathrm{cm}^{-1}\right)$ and carbonyl $\left(\sim 1707 \mathrm{~cm}^{-1}\right)$ of BCP disappeared upon adding PPA (Fig. S4A). Meanwhile, the absorption $\left(\sim 3401 \mathrm{~cm}^{-1}\right)$ ascribed to the stretching vibration of N-H group of PPA blue shift to $\sim 3431 \mathrm{~cm}^{-1}$ and became broaden. And the $\sim 3351 \mathrm{~cm}^{-1}$ absorption peak of N-H group of PPA shifted to higher wavenumber when the gel was formed (Fig. S4B).
Table $2 \mathrm{UV}$-vis absorption peak position of different gels with $0,0.5,1,2.5,5 \mathrm{mg} \mathrm{ml}^{-1} \mathrm{BCP}$; $\mathrm{V}_{\mathrm{PPA}} / \mathrm{V}_{\mathrm{BCP}}=1: 1$

\begin{tabular}{ccc}
\hline Sample code & Absorption peak (nm) \\
\hline BCP/PPA-0 & 270 & 344 \\
BCP/PPA-0.5 & 272 & 344 \\
BCP/PPA-1 & 273 & 344 \\
BCP/PPA-2.5 & 274 & 344 \\
BCP/PPA-5 & 276 & 345 \\
\hline
\end{tabular}

SAXS was used to probe the internal structure of the gel, and the scattering patterns of BCP/PPA hydrogels with different molar ratios were given in Fig. 6C. The scattering intensities indicated these samples were internal heterogeneous, existing aggregates in nanoscale. Meanwhile, the nanostructures of PPA were nearly intact in view of the unchanged scattering intensity, implying that minor addition of BCP only changed slightly the systematic electron density. Moreover, $I(q)$ showed a power-law dependence of $q^{2}$, suggesting the disk-like structure.[46] And the inset profiles of PDDF also indicated that the diameters of the PPA nanoparticles were barely change. Values of $f(r)$ vs. $D$ for the disk-like particles were further plotted in Fig. S5. And the function $(f(r)=p(r) / r)$ which served as a processing strategy but had no actual physical meaning, was more insightful for disk-like particles than $p(r)$.[47] Here, the nearly same thickness $d$ of the particle which could be read directly from the transition point for the five curves (Fig. S5), corroborate deeply that the nanostructures of PPA were nearly intact, as revealed above from the Fig. $6 \mathrm{C}$.

The radius of gyration $\left(R_{g}\right)$ could be derived from the illustration in Fig. $6 \mathrm{C}$ with the same method as above mentioned SAXS analysis in Fig. 3A-B, in order, $19 \mathrm{~nm}, 17 \mathrm{~nm}, 19 \mathrm{~nm}, 18 \mathrm{~nm}, 20 \mathrm{~nm}$, corresponding to BCP/PPA-0, BCP/PPA-0.5, BCP/PPA-1, BCP/PPA-2.5, BCP/PPA-5, respectively. It's noteworthy that no BCP diffraction peak, even for BCP/PPA-5, was founded in XRD results (Fig. S6). Hence, the notable diffraction peaks $\left(\sim 20.3^{\circ}, \sim 27.2^{\circ}\right.$ and $\sim 28^{\circ}$ ) were reasonably ascribed to PPA component. Although this aspect deserve further studying, it's rational that the addition of BCP may not radically change the internal nanoscale structure of the gel.

The rheological behavior of the gel system. The rheological properties were further investigated to understand the molecular movement in the BCP/PPA gel system (Fig. 7). BCP/PPA hydrogels demonstrated a temperature sensitive behavior, and all gels exhibited reducing trend in modulus $\left(\mathrm{G}^{\prime}\right.$ and $\left.\mathrm{G}^{\prime \prime}\right)$ with temperature (Fig. 7A). Generally, the $\mathrm{G}^{\prime}$ was greater than $\mathrm{G}^{\prime \prime}\left(25-35^{\circ} \mathrm{C}\right)$ and reaching consensus in the later stage $\left(>35^{\circ} \mathrm{C}\right)$, indicating a gel viscoelastic behavior dominated by elasticity. As well accepted, the hydrogels' viscous property was primarily attributed to weak and reversible physical interaction, while elasticity was mainly controlled by strong bond or hard stuff.[48] Based on this premise, the BCP/PPA-0.5 hydrogel presented the maximum in $\mathrm{G}^{\prime}$ value. 


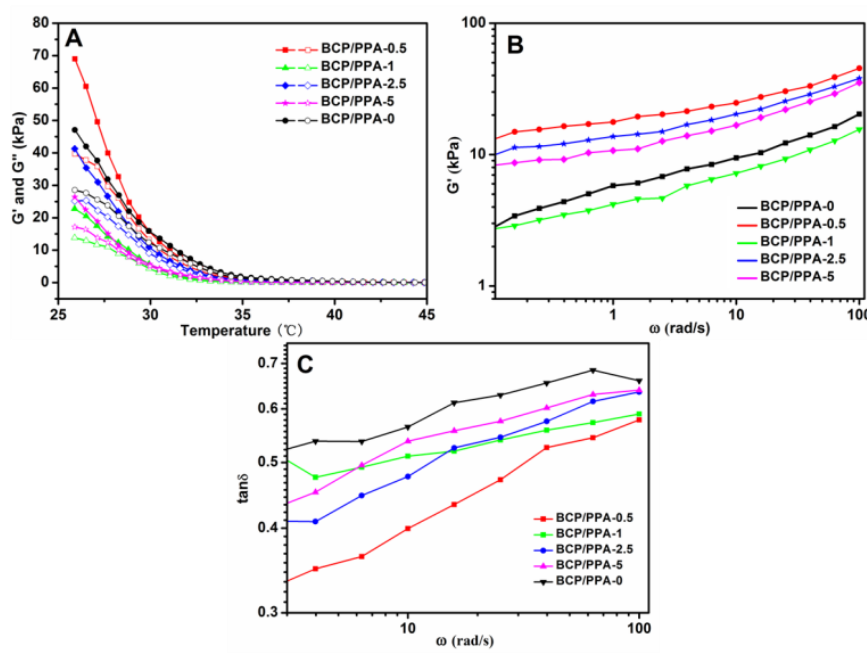

Fig. 7 Rheological measurements of BCP/PPA hydrogels with $0,0.5,1,2.5,5 \mathrm{mg} \mathrm{ml}^{-1}$ BCP: variation in storage modulus $\mathrm{G}^{\prime}$ (solid symbols) and loss modulus $\mathrm{G}^{\prime \prime}$ (open symbols) as a function of temperature (A) and frequency (B). Loss tangent, tan(delta) of hydrogels on frequency sweep (C). $\mathrm{V}_{\mathrm{PPA}} / \mathrm{V}_{\mathrm{BCP}}=1: 1$.

Fig. 7B, 7C showed the frequency dependence of storage modulus $\mathrm{G}^{\prime}$ and loss tangent $(\tan \delta)$. In the frequency sweep, $\mathrm{G}^{\prime}>\mathrm{G}^{\prime \prime}$ (Fig. S7), indicating the formation of gel. $\mathrm{G}^{\prime}$ and $\mathrm{G}^{\prime \prime}$ were augmented with increasing frequency, which was different from classical gel behavior (both $G^{\prime}$ to $G^{\prime \prime}$ values will constant independent of the frequency change). This observation suggested that long-range network structure was not fully developed, and a small length scale structure or a packing of emulsion droplets in the gel system. [49] More specifically, this can be rationalized that the crystallites restrained the longrange arrangement of the network. For the same reason, the BCP/PPA-0.5 hydrogel present the minimal loss tangent $(\tan \delta)$ with frequency (Fig. 7C).

\section{Conclusions}

In summary, we have systemically investigated the aggregation and crystallization behavior of PM-b-PAA under the influence of organic amine PPA. SEM, POM and DLS characterizations indicated that, when varying the BCP/PPA molar ratios, the BPC could form a series of morphologies with different sizes, from sphere, band to sheet. Furthermore, as evidenced clearly by DSC and 2D WAXS measurements, the crystallization of PM block was profoundly restrained by PPA. The aggregation and crystallization behavior was influenced by the adding of PPA which affected the stretching degree of the PAA block through the dual confinements (i.e., chemical and physical confinement). The interaction mechanism of BCP and PPA was further illustrate by UV-vis, FTIR and ${ }^{1} \mathrm{H}$ NMR. In particular, when PPA was increased to a certain amount, hydrogels was accessible. And rheology data indicated that the BCP/PPA- 0.5 hydrogels assumed the maximal storage modulus, and meanwhile the minimum loss tangent. This systematical investigation on PM-b-PAA/PPA is believed to broaden the basic research and practical application of semi-crystalline block copolymers.

\section{Acknowledgement}

This work was supported by the National Science Foundation of China (21072221, 21172252).

\section{References}

[1] R. Liu, Z.Y. Li, W.J. Wang, D. Yuan, C.F. Meng, Q. Wu, F.M. Zhu, Synthesis and selfassembly of amphiphilic star-block copolymers consisting of polyethylene and poly(ethylene glycol) segments, J. Appl. Polym. Sci. 129(4) (2013) 2216-2223.
[2] H.B. Qiu, Y. Gao, V. Du, R. Harniman, M.A. Winnik, I. Manners, Branched Micelles by Living Crystallization-Driven Block Copolymer Self-Assembly under Kinetic Control, J. Am. Chem. Soc. 137(6) (2015) 2375-2385.

[3] F. Li, K.G. Yager, N.M. Dawson, J.H. Yang, K.J. Malloy, Y. Qin, Complementary Hydrogen Bonding and Block Copolymer Self-Assembly in Cooperation toward Stable Solar Cells with Tunable Morphologies, Macromolecules 46(22) (2013) 9021-9031.

[4] S. Jung, W. Kwon, D. Wi, J. Kim, B.J. Ree, Y.Y. Kim, W.J. Kim, M. Ree, Hierarchical Self-Assembly and Digital Memory Characteristics of Crystalline-Amorphous Brush Diblock Copolymers Bearing Electroactive Moieties, Macromolecules 49(4) (2016) 1369-1382.

[5] H.F. Wang, C. Wu, G.M. Xia, Z. Ma, G. Mo, R. Song, Semi-crystalline polymethylene-bpoly(acrylic acid) diblock copolymers: aggregation behavior, confined crystallization and controlled growth of semicrystalline micelles from dilute DMF solution, Soft Matter 11(9) (2015) 1778-1787.

[6] F.H. Schacher, P.A. Rupar, I. Manners, Functional Block Copolymers: Nanostructured Materials with Emerging Applications, Angew. Chem.-Int. Edit. 51(32) (2012) 7898-7921.

[7] X.B. Yang, J. Ge, M. He, Z. Ye, X.F. Liu, J. Peng, F. Qiu, Crystallization and Microphase Morphology of Side-Chain Cross-Linkable Poly(3-hexylthiophene)-block-poly 3-(6hydroxy)hexylthiophene Diblock Copolymers, Macromolecules 49(1) (2016) 287-297.

[8] W.N. He, J.T. Xu, Crystallization assisted self-assembly of semicrystalline block copolymers, Prog. Polym. Sci. 37(10) (2012) 1350-1400.

[9] S.J. Holder, G. Woodward, B. McKenzie, N. Sommerdijk, Semi-crystalline block copolymer bicontinuous nanospheres for thermoresponsive controlled release, RSC Adv. 4(50) (2014) 26354-26358.

[10] R.M. Ho, Y.W. Chiang, S.C. Lin, C.K. Chen, Helical architectures from self-assembly of chiral polymers and block copolymers, Prog. Polym. Sci. 36(3) (2011) 376-453.

[11] Z.S. Ge, S.Y. Liu, Functional block copolymer assemblies responsive to tumor and intracellular microenvironments for site-specific drug delivery and enhanced imaging performance, Chem. Soc. Rev. 42(17) (2013) 7289-7325.

[12] E.L. Kynaston, O.E.C. Gould, J. Gwyther, G.R. Whittell, M.A. Winnik, I. Manners, FiberLike Micelles from the Crystallization-Driven Self-Assembly of Poly(3-heptylselenophene)block-Polystyrene, Macromol. Chem. Phys. 216(6) (2015) 685-695.

[13] R.Q. Song, T.N. Hoheisel, H. Sai, Z. Li, J.D. Carloni, S. Wang, R.E. Youngman, S.P Baker, S.M. Gruner, U. Wiesner, L.A. Estroff, Formation of Periodically-Ordered Calcium Phosphate Nanostructures by Block Copolymer-Directed Self-Assembly, Chem. Mat. 28(3) (2016) 838-847.

[14] J.B. Wang, Y.I. Odarchenko, M. Defaux, J. Lejnieks, D.V. Ahokhin, H. Keul, D.A. Ivanov, M. Moller, A. Mourran, Concurrent Order in a Semi-Crystalline Diblock Copolymer Involving Complexation with a Mesogen, Macromolecules 46(15) (2013) 6159-6168.

[15] Y.Y. Mai, A. Eisenberg, Self-assembly of block copolymers, Chem. Soc. Rev. 41(18) (2012) 5969-5985.

[16] S.F.M. Yusoff, J.B. Gilroy, G. Cambridge, M.A. Winnik, I. Manners, End-to-End Coupling and Network Formation Behavior of Cylindrical Block Copolymer Micelles with a Crystalline Polyferrocenylsilane Core, J. Am. Chem. Soc. 133(29) (2011) 11220-11230.

[17] Z.Z. Tong, Y.M. Li, H.A. Xu, H. Chen, W.J. Yu, W.Q. Zhuo, R.K. Zhang, G.H. Jiang, Corona liquid crystalline order helps to form single crystals when self-assembly takes place in the crystalline/liquid crystalline block copolymers, ACS. Macro. Lett. 5 (2016) 867-872.

[18] C. Kundu, A.K. Dasmahapatra, Effect of block asymmetry on the crystallization of double crystalline diblock copolymers, J. Chem. Phys. 141(4) (2014) 12.

[19] B. Fan, L. Liu, J.H. Li, X.X. Ke, J.T. Xu, B.Y. Du, Z.Q. Fan, Crystallization-driven onedimensional self-assembly of polyethylene-b-poly(tert-butylacrylate) diblock copolymers in DMF: effects of crystallization temperature and the corona-forming block, Soft Matter 12(1) (2016) 67-76.

[20] J.K. Kim, S.Y. Yang, Y. Lee, Y. Kim, Functional nanomaterials based on block copolymer self-assembly, Prog. Polym. Sci. 35(11) (2010) 1325-1349.

[21] R. Liu, Z.Y. Li, B.Y. Mai, Q. Wu, G.D. Liang, H.Y. Gao, F.M. Zhu, Crystalline-coil diblock copolymers of syndiotactic polypropylene-b-poly(ethylene oxide): synthesis, solution self-assembly, and confined crystallization in nanosized micelle cores, J. Polym. Res. 20(2) (2013) 11 .

[22] J. Schmelz, A.E. Schedl, C. Steinlein, I. Manners, H. Schmalz, Length Control and BlockType Architectures in Worm-like Micelles with Polyethylene Cores, J. Am. Chem. Soc. 134(34) (2012) 14217-14225.

[23] N.V. Salim, T. Hanley, Q.P. Guo, Microphase Separation through Competitive Hydrogen Bonding in Double Crystalline Diblock Copolymer/Homopolymer Blends, Macromolecules 43(18) (2010) 7695-7704.

[24] A.M. Mihut, J.J. Crassous, H. Schmalz, M. Drechsler, M. Ballauff, Self-assembly of crystalline-coil diblock copolymers in solution: experimental phase map, Soft Matter 8(11) (2012) 3163-3173.

[25] T. Defize, J.M. Thomassin, M. Alexandre, B. Gilbert, R. Riva, C. Jerome, Comprehensive study of the thermo-reversibility of Diels-Alder based PCL polymer networks, Polymer 84 (2016) 234-242.

[26] J.X. Yang, L. Liu, J.T. Xu, Crystalline Micelles of Block Copolymers, Prog. Chem. 26(11) (2014) 1811-1820.

[27] P.A. Rupar, L. Chabanne, M.A. Winnik, I. Manners, Non-Centrosymmetric Cylindrical Micelles by Unidirectional Growth, Science 337(6094) (2012) 559-562.

[28] J.R. Finnegan, D.J. Lunn, O.E.C. Gould, Z.M. Hudson, G.R. Whittell, M.A. Winnik, I. Manners, Gradient Crystallization-Driven Self-Assembly: Cylindrical Micelles with "Patchy" Segmented Coronas via the Coassembly of Linear and Brush Block Copolymers, J. Am. Chem. Soc. 136(39) (2014) 13835-13844

[29] R.J. Macfarlane, B. Kim, B. Lee, R.A. Weitekamp, C.M. Bates, S.F. Lee, A.B. Chang, K.T. Delaney, G.H. Fredrickson, H.A. Atwater, R.H. Grubbs, Improving Brush Polymer Infrared One-Dimensional Photonic Crystals via Linear Polymer Additives, J. Am. Chem. Soc. 136(50) (2014) 17374-17377.

[30] W.C. Shi, A.L. Hamilton, K.T. Delaney, G.H. Fredrickson, E.J. Kramer, C. Ntaras, A. Avgeropoulos, N.A. Lynd, Creating Extremely Asymmetric Lamellar Structures via Fluctuation-Assisted Unbinding of Miktoarm Star Block Copolymer Alloys, J. Am. Chem. Soc. 137(19) (2015) 6160-6163.

[31] J.J. Crassous, P. Schurtenberger, M. Ballauff, A.M. Mihut, Design of block copolymer micelles via crystallization, Polymer 62 (2015) A1-A13.

[32] W.N. He, J.T. Xu, B.Y. Du, Z.Q. Fan, X.S. Wang, Inorganic-Salt-Induced Morphological Transformation of Semicrystalline Micelles of PCL-b-PEO Block Copolymer in Aqueous Solution, Macromol. Chem. Phys. 211(17) (2010) 1909-1916.

[33] Y.Y. Kim, B. Ahn, S. Sa, M. Jeon, S.V. Roth, S.Y. Kim, M. Ree, Self-Assembly Characteristics of a Crystalline-Amorphous Diblock Copolymer in Nanoscale Thin Films, Macromolecules 46(20) (2013) 8235-8244 
[34] J.X. Yang, B. Fan, J.H. Li, J.T. Xu, B.Y. Du, Z.Q. Fan, Hydrogen-Bonding-Mediated Fragmentation and Reversible Self-assembly of Crystalline Micelles of Block Copolymer, Macromolecules 49(1) (2016) 367-372.

[35] Y.C. Chen, K. Zhang, X.J. Wang, F.W. Zhang, J.H. Zhu, J.W. Mays, K.L. Wooley, D.J. Pochan, Multigeometry Nanoparticles: Hybrid Vesicle/Cylinder Nanoparticles Constructed with Block Copolymer Solution Assembly and Kinetic Control, Macromolecules 48(16) (2015) 5621-5631.

[36] R. Du, J.X. Wu, L. Chen, H. Huang, X.T. Zhang, J. Zhang, Hierarchical Hydrogen Bonds Directed Multi-Functional Carbon Nanotube-Based Supramolecular Hydrogels, Small 10(7) (2014) 1387-1393.

[37] O. Glatter, Modern Methods of Data Analysis in Small-Angle Scattering and Light Scattering, Springer Netherlands1995.

[38] H.C. Lu, Y. Xue, Q.L. Zhao, J. Huang, S.G. Xu, S.K. Cao, Z. Ma, Well-defined amphiphilic polymethylene-b-poly(acrylic acid) diblock copolymers: New synthetic strategy and their self-assembly, J. Polym. Sci. Pol. Chem. 50(17) (2012) 3641-3647.

[39] W. Qu, X.Q. Zhu, J.H. Chen, L. Niu, D.H. Liang, X.H. Fan, Z.H. Shen, Q.F. Zhou, Synthesis and Characterization of a Mesogen-Jacketed Polyelectrolyte, Macromolecules 47(8) (2014) 2727-2735.

[40] X.Q. Zhu, The SAXS Guide, Anton Paar GmbH. Printed in Austria., 2011.

[41] Y. Komori, S. Hayashi, Reversible color change of chromophores in zeolites by direct interaction with alkali metal cations, Langmuir 19(6) (2003) 1987-1989.

[42] X.Q. Zhang, Z.G. Chi, B.J. Xu, H.Y. Li, Z.Y. Yang, X.F. Li, S.W. Liu, Y. Zhang, J.R. Xu, Synthesis of blue light emitting bis(triphenylethylene) derivatives A case of aggregationinduced emission enhancement, Dyes Pigment. 89(1) (2011) 56-62.

[43] M.A. Jordaan, P. Singh, B.S. Martincigh, A combined TD-DFT and spectroscopic investigation of the solute-solvent interactions of efavirenz, Spectroc. Acta Pt. A-Molec. Biomolec. Spectr. 157 (2016) 204-210

[44] R. Pelton, Polyvinylamine: A Tool for Engineering Interfaces, Langmuir 30(51) (2014) 15373-15382.

[45] X.H. Feng, R. Pelton, M. Leduc, S. Champ, Colloidal complexes from poly(vinyl amine) and carboxymethyl cellulose mixtures, Langmuir 23(6) (2007) 2970-2976.

[46] S. Venkataraman, Z.A. Chowdhury, A.L. Lee, Y.W. Tong, I. Akiba, Y.Y. Yang, Access to Different Nanostructures via Self-Assembly of Thiourea-Containing PEGylated Amphiphiles, Macromolecular Rapid Communications. 34 (8) (2013) 652-658.

[47] O. Glatter, O. Kratky, Small Angle X-ray Scattering. London: Academic Press, 1982.

[48] Y.Y. Zhang, Y.M. Li, W.G. Liu, Dipole-Dipole and H-Bonding Interactions Significantly Enhance the Multifaceted Mechanical Properties of Thermoresponsive Shape Memory Hydrogels, Adv. Funct. Mater. 25(3) (2015) 471-480.

[49] P.A.G. Soares, J. de Seixas, P.B.S. Albuquerque, G.R.C. Santos, P.A.S. Mourao, W. Barros, M.T.S. Correia, M.G. Carneiro-da-Cunha, Development and characterization of a new hydrogel based on galactomannan and kappa-carrageenan, Carbohydr. Polym. 134 (2015) 673-679. 


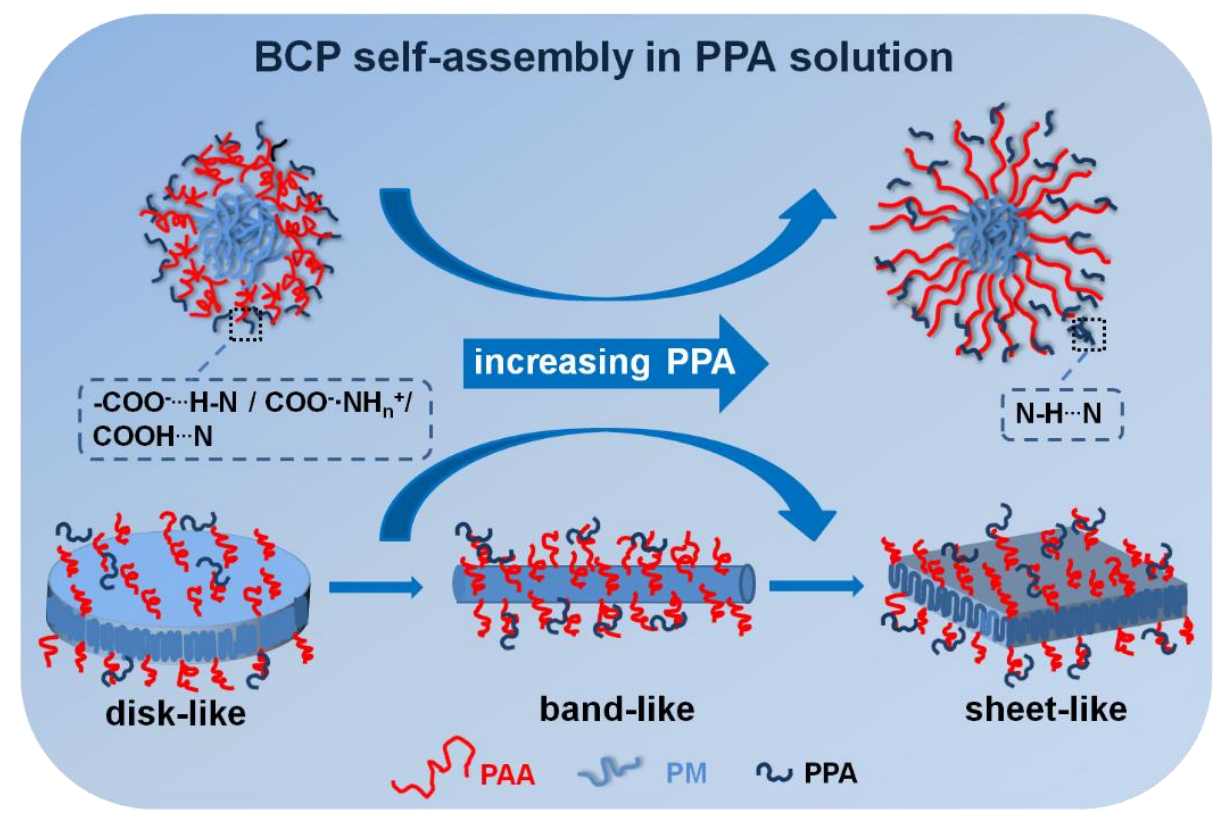

Table of Contents

The aggregation and confined crystallization behavior of polymethylene-b-poly (acrylic acid) diblock copolymers (PM-b-PAA) under the influence of polyethylene polyamine (PPA). 